\title{
Financial Performance Of Wide-Moat Companies
}

David P. Boyd (e-mail: d.boyd@neu.edu), Northeastern University

\begin{abstract}
Morningstar has identified 85 companies with wide economic moats. According to Morningstar these firms enjoy structural advantages that create shareholder value. This paper confirms the historical outperformance of these companies.
\end{abstract}

\section{INTRODUCTION}

$\mathscr{Q}$ nder its Bellwether 50 panoply, Morningstar includes firms with an especially wide economic moat. Because of their structural defenses, these companies enjoy sustainable competitive advantage. They can repel invaders intent on purloining market share.

The dictionary defines a "moat" as a "deep, wide ditch surrounding a fortification." While dry ditches were regarded as better than none, wide-water moats afforded optimal protection from assault. These water barriers were more than a dozen feet wide and could measure 30 feet in depth. Some of these waterways even contained submerged, jagged stakes to impede prospective assailants.

The notion of an economic moat finds early expression in Warren Buffet. As investment vehicles Buffet selects firms with "economic castles protected by unbreachable moats" (Morningstar, 2004, p. 10). In his work on competitive strategy, Michael Porter (1980) has identified many of the features that characterize such firms, and Morningstar acknowledges a debt to Porter in its classification scheme.

According to Morningstar (Sellers, 2003), there are four basic moats (Figure 1). The first type stems from economies of scale and low cost production. These scale economies are based on infrastructure capabilities and distribution networks. This cost leadership can insure wide-moat status despite a product's commodity flavor. A noteworthy example is Dell with its direct sales distribution of computer hardware.

High customer-switching costs can also confer wide-moat status. By delivering quality product in a timely manner, a company can engrain its customer base. This loyal clientele would require considerable incentive to switch to a competitor. Physicians, for example, are slow to forego customary protocols. When retraining is necessary, as it was for Zimmer's two-hip procedure, the company made physicians sign exclusivity contracts. At the Chicago Mercantile Exchange clearing customers are apt to stay "sticky" because the "Merc" assumes all counterparty risk.

Intangible assets represent the third kind of economic moat. This rubric subsumes everything from chip design to drug compounds. Medtronic's intellectual property portfolio is an example. Leveraging its knowledge of the heart's electrical conduction system, Medtronic has extended its cardiovascular "signal technology" to neurological and physiological products. Government permits also serve as intangible assets. Licensing requirements can bar the entry of potential competitors. By legally staving off competition, those already in the fold can secure their hold. Morningstar suggests brand franchise is another form of intangible asset since name recognition can confer pricing power. Some would argue whether brand automatically ensures competitive advantage. In its most recent poll, Business Week (2004) accorded Coca-Cola distinction as the world's premier brand. One reader responded tersely: "Brand is garbage. Performance is everything" (p. 26). Yet firms such as Harley-Davidson are profoundly evocative in their imagery. Harley is determined to preserve and broaden this halo, 
having recently lowered its bike seats in an attempt to woo women. Finally, Morningstar avers that a unique corporate culture can widen a moat and contribute to performance. Again, corporate culture alone might not be a harbinger of success. Morningstar itself assigns narrow moats to some firms with distinctive cultures. Jabil Circuit is highly regarded for its horizontal work model with dedicated customer teams while Danaher has a culture of continuous improvement based on Toyota's legendary practices. Yet Morningstar considers the moat of each firm to be narrow.

Network economics is the final determinant of wide-moat status. The network effect is the least evident of the four types but is manifest in a cadre of companies. EBay is an exemplary example. Its 114 million registered users eviscerate competitive threat. As the network subsumes more buyers and sellers, it enhances the value for every user. Morningstar suggests that the network effect can also be observed in software products that glue correspondents through a common medium. Microsoft has done so through its ubiquitous operating system and Autodesk has provided a liaison for many construction designers.

\section{DO MOATS MATTER?}

Morningstar would counsel investors to be wary of splendid castles with shallow moats. The allure of such edifices will prove ephemeral. Morningstar cites PalmOne whose market value plummeted from $\$ 30$ billion in the fall of 2000 to less than $\$ 2$ billion today. If such stocks populate a portfolio, they should be there solely for trading purposes. Only wide-moat companies will sustain success over the long haul. Morningstar cautions readers to shun flash and seize cash. Kenny Rogers' gambling man sings a similar admonition: "You gotta know when to hold 'em and know when to fold 'em."

While Morningstar's premise is intuitively appealing, it should nonetheless undergo empirical scrutiny. Morningstar postulates that over a five-year period wide-moat stocks will generate shareholder value through increased earnings power and price appreciation. Buffet and Morningstar further maintain that these firms will demonstrate stability in their earnings trajectory. If such observations prove accurate, they will lend credence to Morningstar's claim that wide-moat stocks are for buy and hold. Moreover, it is timely to test Morningstar's thesis because investment houses are now under mandate to consider "independent" research.

\section{DATA ANALYSIS}

Morningstar has compiled a "Bellwether 50" list of large-caps with wide economic moats. More recently, it has also devised a compendium of 35 wide-moat mid-caps. The present study will test the aggregate performance of these two sets over a five-year period as well as a select subset.

Inclusion on Morningstar's wide-moat roster does not presume a "should buy" recommendation. The "Bellwether 50" and the 35 mid-caps are not so much "buy" lists as "watch" lists (Larson, 2003). Even if a company's moat remains wide and deep, growth potential can already be priced into its shares. Wide-moat stocks, though, do carry a connotation of "should have bought" - and perhaps "buy" if they hit a rough patch of road. When that occurs, Morningstar enjoins its readers: "If it feels bad, do it." Investors should poise their bats for such "fat pitches" (Sellers, 2004). In swinging, investors should exercise caution in view of Morningstar pronounced bias toward low price. Its research analysts adeptly underscore potential concerns, especially for fully priced firms. Yet these same analysts tend to tout companies when they stumble or even tumble. Instances range from Devry to Krispy Kreme. In purchasing such companies, might investors ignore the very events that precipitated the plunge?

The study employed three measures to track financial performance. The first two measures, growth in earnings per share (EPS) and stability of earnings per share, are derived from First Call. The EPS growth number represents annualized earnings per share growth over the past five years. The earnings stability number reflects the consistency of earnings per share growth over the past five years. The lower the number, the more uniform growth has been. For companies showing predictable earnings streams, there is a smaller than average percentage difference between reported EPS and trend EPS. Combined with earnings growth data, the stability figure provides a multi-dimensional view of earnings growth. These earnings dimension numbers go through the June Quarter of 
2004. Value Line's measure of Price Growth Persistence is used to measure Stock Growth. This number measures the historic tendency of a stock to show persistent share appreciation compared to the average stock. Value Line Persistence ratings range from 100 (highest) to 5 (lowest). The Value Line numbers used in this study are those closest to the end of the June 2004 quarter.

\section{Selection Of A Subset}

(Table 1).

The author has identified a subset of seven that seems particularly reflective of Morningstar's criteria

\section{Table 1: Types Of Economic Moats}

1. $\quad$ Economies of Scale/Low-Cost Producer - e.g. Teva Pharmaceuticals

2. High Customer-Switching Costs - e.g. Kinder Morgan

3. Intangible Assets

a. Patent Protection - e.g. Qualcomm

b. Government Permits - e.g. Stericycle

c. Brand Franchise - e.g. Weight Watchers International

d. Unique Corporate Culture - e.g. Expeditors International of WA

4. $\quad$ Network Effect - e.g. Adobe

\section{Economies Of Scale}

Teva boasts the drug industry's largest generic pipeline of 109 abbreviated applications. This funnel equates to $\$ 67$ billion in branded-drug sales. Changes to Medicare will facilitate generic approval and may result in a 2006 bonanza. Teva's distribution channels are well established, and the firm has a foothold in the nascent field of generic biologics.

\section{High Customer Switching Costs}

Kinder Morgan owns 35,000 miles of pipes and collects a toll on all the natural gas moving through them. Since regulatory approvals effectively pose barriers, Kinder's customers have few alternatives. Service contracts tend to be of long duration. Merrill Lynch says of the company: "It is not a household name but they quietly touch a lot of households" (Brothwell, 2004, p. 2).

\section{Intangible Assets - Patent Protection}

Qualcomm is another toll collector, exacting a royalty for each CDMA phone sold. This tariff garners the company 90 percent pre-tax margins. Given low teledensity rates, Qualcomm views China and India as enormous emergent markets. It also expects to benefit from Europe's move to W-CDMA.

\section{Intangible Assets - Government Permits}

Stericycle transports and treats medical waste from 304,000 medical centers, enjoying revenue 17 times greater than its closest rival. The company's scale allows it to be the low-cost producer. Hospitals readily outsource the complex regulatory and legal issues of toxic disposal. As the population turns more silver, waste removal will increase.

\section{Intangible Assets - Brand Franchise}

As the "low-carb" fad starts to fade, dietary flexibility and dietary safety may prove a sustainable 
advantage for Weight Watchers. The social bonding that occurs in meetings induces three quarters of attendees to return at some point. This company has few capital requirements and benefits from a variable cost structure.

\section{Intangible Assets - Unique Corporate Culture}

Morningstar lauds Expeditors International for its unique, incentive-based culture. This freightforwarding firm melds company finances and employee compensation. Since base salaries are modest, employees look toward a bonus based on the company's pretax profit. Individual offices also retain a portion of operating profit for allocation to their own staff. Credit Suisse calls Expeditors "the gem of the global logistics industry" (Barnes and Gardner, 2004, p. 98).

\section{The Network Effect}

Adobe has created the de facto standard for developing and deploying electronic documents. More than 500 million computers have downloaded its Acrobat product. Moreover, Photoshop and Illustrator have become a preferred conduit for creative professionals who see no reason to switch.

\section{STUDY FINDINGS AND LIMITATIONS}

Morningstar's segmentation of wide moat stocks achieved historical outperformance along all study dimensions. Both the large-cap and mid-cap samples demonstrated robust earnings growth and earnings stability. As expected, such strong historical performance was associated with share price appreciation. Relative to the market, the aggregate appreciation of large-caps (Table 2) surpassed more than 85 percent of all stocks and the midcaps (Table 3) more than 78 percent. While there were individual laggards on both lists, they were relatively few in number. The author's subset (Table 4) demonstrated the most pronounced gains. All three lists would have handily surpassed the $\mathrm{S} \& \mathrm{P}$ benchmark during the period of -2.21 .

Since Morningstar's approach seems to have merit, ongoing studies should test it further. In particular, if researchers can deduce numeric scores to represent moat width, they can determine whether such numbers predict absolute share performance. For example, one might hypothesize that companies with an overlapping matrix of multiple moats outperform companies with single moats. A firm like Stericycle would exemplify scale, sticky customers and intangible assets. Most Japanese castles had multiple moats, thereby compounding the challenge for opposing armies.

The Morningstar's Bellwether 50 roster has remained relatively immutable during its three-year existence as has the more recent mid-cap list (Larson, 2003). A more persuasive study will occur when the lists themselves can claim longevity of five years. Then year five year stock measurements can commence with the origination of the Morningstar list. After all, the real key is to spot a stock before an appreciable advance.

Should more extensive studies validate Morningstar's segmentation, researchers should reflect on an inherent dilemma. Morningstar considers wide-moat characteristics to be "long-term structural advantages" (Sellers, 2003a, 2004). This conviction minimizes the importance of leadership. Morningstar concurs with Peter Lynch's observation that some companies can make money even with a monkey at the helm - and such a realization is reassuring because this situation might very well occur. This is a digestively difficult notion for these times. Today's paucity of leaders suggests a compelling need for leadership. It is the province of leadership to ensure that sustainable competitive advantages are in place. Stock pickers must also become time travelers, fully cognizant that the wide moats of today may become the dry ditches of tomorrow. The sage investor will prospect for arenas where new companies can build wide moats. Such explorers will scan for emergent secular themes and then search for companies strategically positioned to enact those themes. If Morningstar lists are to claim relevancy, in another decade the roster may reflect water purification, homeland security, digital rights, health care information systems, "silver tech" at home medical devices, RFID technology and a host of other themes that visionaries sense even if they do not yet fully see. 


\section{REFERENCES}

1. Barnes, John and Gardner, Matthew. 2004. Half full or half empty? Credit Suisse First Boston, July 14.

2. $\quad$ Brothwell, Sam. 2004. Kinder Morgan inc. Merrill Lynch, July 28.

3. $\quad$ Business Week. 2004. Readers report. Business Week, August 30.

4. Larson, Paul. 2004. "The case for wide-moat stocks". Morningstar.com, March 26.

5. Morningstar. 2004. StockInvestor reader's guide. Chicago, IL: Morningstar, Inc.

6. $\quad$ Porter, Michael E. 1980. "Competitive strategy". New York: Free Press, 1980.

7. Sellers, Mark A. 2003. The four principles of profitable investing. Chicago, IL: Morningstar, Inc.

$8 . \quad$ 2003a. Four companies with almost-wide moats. Morningstar.com, August 6.

$9 . \quad$ 2004. The fat-pitch approach to stock investing. Morningstar.com, January 28.

Figure 1: Economic Moats

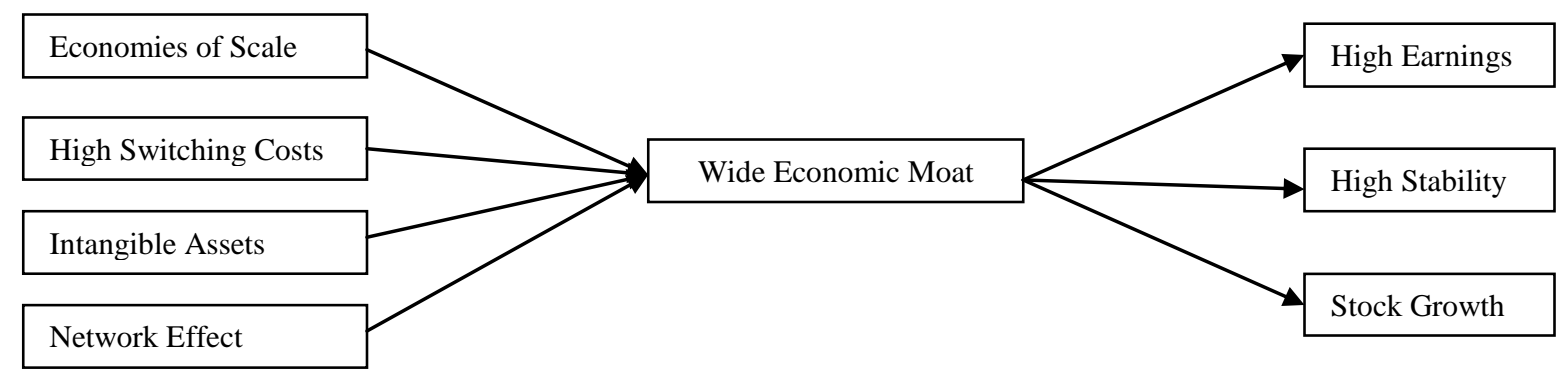


Table 2: Morningstar Bellwether 50

\begin{tabular}{|c|c|c|c|}
\hline Company Name & Historical Earnings & Historical Stability & Stock Growth \\
\hline SLM $* *$ & 18.11 & 5.51 & 100 \\
\hline Comcast** & NA & NA & NA \\
\hline Pfizer** & 18.89 & 9.03 & 85 \\
\hline Anheuser-Busch** & 11.87 & 31.15 & 95 \\
\hline Paychex $* *$ & 13.27 & 7.73 & 80 \\
\hline eBay* & 108.95 & 22.89 & 65 \\
\hline Genentech* & 26.35 & 8.23 & NMF \\
\hline Amgen & 17.24 & 8.80 & 80 \\
\hline Sysco & 19.56 & 9.57 & 95 \\
\hline Medtronic & 15.96 & 3.69 & 95 \\
\hline AstraZeneca PLC & -1.53 & 19.28 & NA \\
\hline Home Depot & 16.03 & 12.93 & 65 \\
\hline Johnson \& Johnson & 16.00 & 13.68 & 95 \\
\hline Applied Materials & -22.11 & 120.78 & 70 \\
\hline Wal-Mart Stores & 13.47 & 12.52 & 80 \\
\hline United Parcel Service & 3.66 & 7.50 & NMF \\
\hline Microsoft & 8.77 & 7.07 & 65 \\
\hline Berkshire Hathaway & 51.51 & 138.74 & 95 \\
\hline Coca-Cola & 11.07 & 14.67 & 40 \\
\hline Wells Fargo & 13.37 & 2.24 & 100 \\
\hline Marsh \& McLennan & 12.13 & 11.47 & 90 \\
\hline First Data & 20.69 & 9.32 & 75 \\
\hline Altria Group & 8.47 & 6.96 & 60 \\
\hline Automatic Data Processing & 7.33 & 16.86 & 80 \\
\hline Citigroup & 9.77 & 9.57 & 90 \\
\hline Eli Lilly \& Company & 2.60 & 6.86 & 90 \\
\hline Colgate-Palmolive & 13.36 & 3.71 & 100 \\
\hline Fifth Third Bancorp & 16.28 & 4.28 & 100 \\
\hline AFLAC & 17.11 & 2.91 & 100 \\
\hline PepsiCo & 12.50 & 9.38 & 85 \\
\hline Bank of New York & -5.04 & 32.94 & 80 \\
\hline American Express & 6.21 & 32.81 & 85 \\
\hline General Dynamics & 10.38 & 5.41 & 95 \\
\hline Dell & 8.97 & 12.13 & 75 \\
\hline Wrigley Wm Jr & 10.19 & 6.62 & 90 \\
\hline State Street & 11.60 & 5.83 & 95 \\
\hline Progressive & 91.42 & 87.89 & 90 \\
\hline United Technologies & 15.03 & 17.18 & 100 \\
\hline Walgreen & 16.40 & 14.09 & 100 \\
\hline Procter \& Gamble & 12.03 & 16.61 & 85 \\
\hline Boston Scientific & 6.25 & 15.88 & 60 \\
\hline Capital One Financial & 31.31 & 5.08 & 100 \\
\hline 3M Company & 9.94 & 6.82 & 95 \\
\hline Gillette & 5.52 & 16.10 & 40 \\
\hline Harley-Davidson & 30.29 & 6.28 & 90 \\
\hline Hershey Foods & 13.79 & 29.80 & 85 \\
\hline Biogen IDEC & 48.83 & 27.00 & 90 \\
\hline Avon Products & 14.74 & 24.28 & 100 \\
\hline Intel & -10.11 & 44.66 & 75 \\
\hline Stryker & 28.63 & 6.34 & 100 \\
\hline Bellwether 50 Average & 17.08 & 19.41 & 84.89 \\
\hline
\end{tabular}


Table 3: Mid-Caps With Moats

\begin{tabular}{|c|c|c|c|}
\hline Company Name & Historical Earnings & Historical Stability & Stock Growth \\
\hline Fidelity National Fin** & 44.35 & 27.68 & 85 \\
\hline Iron Mountain** & 82.79 & 26.24 & 70 \\
\hline Biomet* & 18.31 & 2.23 & 95 \\
\hline Getty Images* & 26.47 & 54.64 & 65 \\
\hline Autodesk* & 7.40 & 66.74 & 30 \\
\hline Renaissance Re Holdings & 39.72 & 17.70 & NA \\
\hline Eaton Vance & 8.18 & 18.29 & 90 \\
\hline Weight Watchers & 42.43 & 29.72 & NMF \\
\hline Northern Trust & 2.08 & 10.74 & 75 \\
\hline Equifax & -0.84 & 12.41 & NMF \\
\hline Jack Henry \& Associates & 12.82 & 16.33 & 85 \\
\hline Intuit & 28.50 & 14.36 & 75 \\
\hline Fiserv & 21.39 & 3.81 & 100 \\
\hline Washington Post & 5.09 & 61.34 & 100 \\
\hline Kinder Morgan & 35.58 & 15.74 & 80 \\
\hline IMS Health & 9.32 & 13.83 & 40 \\
\hline CH Robinson & 18.93 & 5.61 & 95 \\
\hline Guidant & 14.37 & 6.13 & 90 \\
\hline Cedar Fair LP & -1.97 & 7.72 & 50 \\
\hline McGraw-Hill Companies & 13.25 & 85.68 & 100 \\
\hline Teva Pharmaceuticals & 42.48 & 5.72 & NA \\
\hline John Wiley \& Sons & 11.26 & 44.03 & 95 \\
\hline Dow Jones \& Co & -24.87 & 66.75 & 55 \\
\hline Pitney Bowes & 0.85 & 5.54 & 65 \\
\hline Moody's & 32.62 & 8.13 & NMF \\
\hline Cintas & 8.65 & 3.42 & 95 \\
\hline Blackrock & 22.52 & 3.21 & NA \\
\hline International Speedway & 21.62 & 28.09 & 85 \\
\hline Block H\&R & -13.28 & 543.12 & 45 \\
\hline Expeditors Intl & 20.64 & 14.14 & 100 \\
\hline Stericycle & 41.56 & 11.04 & 90 \\
\hline Gentex & 11.99 & 9.64 & 95 \\
\hline Total System Services & 18.12 & 7.15 & 80 \\
\hline Chicago Mercantile & NA & NA & NA \\
\hline Adobe Systems & 10.06 & 17.58 & 55 \\
\hline Mid-Cap Average & 18.60 & 37.19 & 78.03 \\
\hline
\end{tabular}

Table 4: Subset Of Wide-Moat Stocks

\begin{tabular}{|l|c|c|c|}
\hline Company Name & Historical Earnings & Historical Stability & Stock Growth \\
\hline Teva Pharmaceutical & 42.48 & 5.72 & NA \\
\hline Kinder Morgan & 35.58 & 15.74 & 80 \\
\hline Qualcomm & 16.99 & 18.37 & 75 \\
\hline Stericycle & 41.56 & 11.04 & 90 \\
\hline Weight Watchers & 42.43 & 29.72 & NMF \\
\hline Expeditors International & 20.64 & 14.14 & 100 \\
\hline Adobe Systems & 10.06 & 17.58 & 55 \\
\hline Subset Average & 29.96 & 16.04 & 80 \\
\hline
\end{tabular}

**buy* sell 
NOTES 